\title{
Relaxed InAsP layers grown on step graded InAsP buffers by solid source MBE
}

\author{
M. K. Hudait ${ }^{1}$, Y. Lin ${ }^{1}$, C. L. Andre ${ }^{1}$, P. M. Sinha ${ }^{1}$, C. A. Tivarus ${ }^{2}$, J. P. Pelz ${ }^{2}$, D. M. Wilt ${ }^{3}$, \\ and S. A. Ringel ${ }^{1}$ \\ ${ }^{1}$ Department of Electrical Engineering, The Ohio State University, 2015 Neil Avenue, \\ Columbus, OH 43210, USA \\ ${ }^{2}$ Department of Physics, The Ohio State University, Columbus, OH 43210, USA \\ ${ }^{3}$ NASA Glenn Research Center, Cleveland, OH 44135, USA
}

\section{ABSTRACT}

Si-doped $\operatorname{In} \mathrm{As}_{\mathrm{x}} \mathrm{P}_{1-\mathrm{x}}$ layers with As mole fractions ranging from 0.05 to 0.50 were grown on $\operatorname{InAs} \mathrm{P}_{\mathrm{x}} \mathrm{P}_{1-\mathrm{x}}$ step-graded buffer layers on InP substrates by solid source molecular beam epitaxy. The growth parameters consisted of a P:In flux ratio of 7:1, a growth temperature of $\sim 485^{\circ} \mathrm{C}$, a growth rate of $2.2 \AA / s$, and an As:In flux ratio of $0.37-2.36$ for varying As mole fractions. The As mole fraction and the layer relaxation were determined using triple axis $\mathrm{x}$-ray diffraction measurements. Near complete relaxation (>93\%) was achieved for all Si-doped $\operatorname{In} \mathrm{As}_{\mathrm{x}} \mathrm{P}_{1-\mathrm{x}}$ epilayers. The structural morphology indicated that the $\operatorname{In} \mathrm{As}_{\mathrm{x}} \mathrm{P}_{1-\mathrm{x}}$ graded buffer layers were effective in relieving the lattice mismatch strain as evidenced by a well-developed crosshatch morphology and low rms surface roughness. The electron concentration, mobility, and Si donor activation energy for each $\operatorname{InAs}_{\mathrm{x}} \mathrm{P}_{1-\mathrm{x}}$ composition were determined using temperature dependent Hall measurements. At a constant electron carrier concentration of $\sim 3.5 \times 10^{16} \mathrm{~cm}^{-3}$, the $300 \mathrm{~K}$ carrier mobility increased from 2700 to $4732 \mathrm{~cm}^{2} / \mathrm{V}$-sec with increasing As mole fraction from 0.05 to 0.50 .

\section{INTRODUCTION}

In $\mathrm{As}_{\mathrm{x}} \mathrm{P}_{1-\mathrm{x}}$ alloys are receiving attention for electronic and optoelectronic applications due to the wide range of attainable bandgap energies from $0.36 \mathrm{eV}$ to $1.35 \mathrm{eV}$. Experimental determination of both the electronic and structural properties of bulk, relaxed InAsP layers at various bandgap energies, thus varying As mole fractions, are critical for attaining optimum device performance. Growth studies of strained, mixed-anion material systems, such as $\operatorname{In} \mathrm{As}_{x} \mathrm{P}_{1-}$ ${ }_{x} / \mathrm{InP}$ [1], GaAs $\mathrm{P}_{1-x} / \mathrm{GaP}$ [2], and $\mathrm{GaAs}_{\mathrm{x}} \mathrm{P}_{1-x} / \mathrm{GaAs}$ [3] indicate that the strain at the surface of the growing thin film modifies the growth dynamics in order to reduce the strain in the film. For strained InAs $\mathrm{P}_{\mathrm{x}-\mathrm{x}}$, this is achieved by a reduced incorporation coefficient of As into the alloy and also an As-P exchange reaction that produces rough interfaces [4,5]. This paper presents a systematic study of structural and electronic properties of relaxed Si-doped $\operatorname{InAs}{ }_{x} \mathrm{P}_{1-\mathrm{x}}$ alloys grown on step graded InAs $\mathrm{P}_{1-\mathrm{x}}$ buffers by solid source molecular beam epitaxy (SSMBE) and the dependence of the carrier concentration, mobility, and Si donor activation energy on As composition in InAs $\mathrm{P}_{1-\mathrm{x}}$ alloys.

\section{EXPERIMENTAL PROCEDURE}

Si-doped InAs $\mathrm{P}_{1-\mathrm{x}}$ layers with As mole fraction ranging from 0.05 to 0.50 were grown on InAs $\mathrm{P}_{1-\mathrm{x}}$ step-graded buffer layers on (100) InP substrates using a SSMBE system equipped with conventional Group III cells and valved cracker sources for both arsenic and phosphorous. To accommodate the large lattice mismatch, $1.3 \%$ with respect to InP for $\mathrm{x}=0.40$, films were grown using step graded buffer layers. For the In $\mathrm{As}_{0.4} \mathrm{P}_{0.6}$ film, the final $1.5 \mu \mathrm{m}$ Si-doped layer was grown on an unintentionally doped step graded buffer consisting of $0.2 \mu \mathrm{m} \operatorname{InAs} \mathrm{s}_{0.4} \mathrm{P}_{0.6}$ $/ 0.4 \mu \mathrm{m} \operatorname{In} \mathrm{As}_{0.35} \mathrm{P}_{0.65} / 0.4 \mu \mathrm{m} \operatorname{InAs} s_{0.32} \mathrm{P}_{0.68} / 0.4 \mu \mathrm{m} \operatorname{InAs} s_{0.21} \mathrm{P}_{0.79}$ layers on an InP substrate. Similarly, other films were grown using appropriate $\operatorname{InAs}_{x} \mathrm{P}_{1-\mathrm{x}}$ buffer layers. These buffers layers 
help minimize the threading dislocation density in the Si-doped $\operatorname{In} \mathrm{As}_{\mathrm{x}} \mathrm{P}_{1-\mathrm{x}}$ epi-layers of interest and thus may improve both the structural and electronic quality of the material. These films were grown after the growth of a $0.2 \mu \mathrm{m}$ thick unintentionally doped InP layer at $\sim 485^{\circ} \mathrm{C}$ under a stabilized $\mathrm{P}_{2}$ flux with $\left(\mathrm{P}_{2} / \mathrm{In}=24: 1\right)$. Next, the $\mathrm{P}_{2}$ flux was reduced to the required value $\left(\mathrm{P}_{2} / \mathrm{In}\right.$ ratio of 7/1) and the As valve was opened in order to achieve the appropriate $\operatorname{In} \operatorname{As}_{\mathrm{X}} \mathrm{P}_{1-\mathrm{x}}$ composition. The exposure time of As on the InP surface was minimized in order to avoid the formation of $\operatorname{InAs} \mathrm{A}_{\mathrm{x}} \mathrm{P}_{1-\mathrm{x}}$ layer on the InP surface. The growth rate and the growth temperature for the InAs $\mathrm{P}_{\mathrm{x}} \mathrm{P}_{1-\mathrm{x}}$ layers were $\sim 2.20 \AA / \mathrm{s}(0.75 \mathrm{ML} / \mathrm{s}$, as determined by RHEED intensity oscillations) and $\sim 485^{\circ} \mathrm{C}$, respectively. The surface morphology of $\operatorname{InAs}_{\mathrm{x}} \mathrm{P}_{1-\mathrm{x}}$ layers was recorded by Nomarski microscopy and atomic force microscopy (AFM). Using a triple axis x-ray diffractometer, both symmetric and asymmetric reciprocal space maps were generated in order to determine the relaxation of each layer and the As composition. Hall effect measurements were performed by the Van der Pauw method and the mobility was calculated assuming a Hall factor, $\mathrm{r}_{\mathrm{H}}$, of 1 . The carrier concentration, mobility, and Si donor activation energy for each $\operatorname{InAs}_{\mathrm{x}} \mathrm{P}_{1-\mathrm{x}}$ composition were determined using temperature dependent Hall measurements in the temperature range of $20 \mathrm{~K}$ to $300 \mathrm{~K}$.

\section{RESULTS AND DISCUSSION}

\section{Determination of As composition in $\operatorname{InAs} \mathbf{s}_{\mathbf{x}} \mathbf{P}_{1-\mathrm{x}}$ layers using reciprocal space map}

Triple-axis $\mathrm{x}$-ray diffraction (TAD) is able to provide information on the structural quality and chemical composition of the individual layers. This technique is important for determination of the relaxation and the lattice tilt between the epilayer lattice planes with respect to the lattice planes of the substrates for both pseudomorphic and relaxed layers [6]. Relaxation, magnitude and direction of epitaxial tilt, and chemical composition can be quantified by reciprocal space map (RSM) near the reciprocal lattice point (RLP) of a symmetric and asymmetric reflection [6]. From the symmetric RSM (004), we measure the angular separation between the substrate and epilayer peaks $\Delta \theta_{(004)}$ to solve for the epilayer $d_{004}$ spacing and the out-of-plane lattice parameter, $a_{\perp}$

$$
d_{004, \text { layer }}=d_{004, \text { substrate }} \pm \frac{\lambda}{2 \sin \left(\Delta \theta_{(004)}\right)} \quad, \quad a_{\perp}=4 d_{004}
$$

where $\lambda$ is the wavelength of x-ray source. The in-plane lattice parameter $a_{\|}$is measured from the asymmetric RSM. Considering the RSM (224), the separation between the substrate and the epilayer peaks is measured along the [220] direction. From the absolute lattice parameter measurement we can determine $d_{224}$ of the layer from the peak separation. For a cubic material, the in-plane lattice parameter is given by,

$$
d_{224, \text { layer }}=d_{224, \text { substrate }} \pm \frac{\lambda}{2 \sin \left(\Delta \theta_{(224)}\right)}, \quad a_{\|}=2 \sqrt{2\left(d_{224}^{-2}-d_{004}^{-2}\right)^{-1}}
$$

The relaxed lattice parameter and the relaxation is then defined by the following equations,

$$
a_{\text {layer }}=\frac{1-v}{1+v} a_{\perp}+\frac{2 v}{1+v} a_{\|}, \quad \text { Relaxation }=\frac{\left(a_{\|}-a_{o}\right)}{\left(a_{\text {layer }}-a_{o}\right)}
$$

where $v$ is the Poisson's ratio and $a_{o}$ is the substrate lattice parameter. The composition of each $\operatorname{In} \mathrm{As}_{\mathrm{x}} \mathrm{P}_{1-\mathrm{x}}$ layer and the layer Poisson's ratio is then given by,

$$
a_{\text {layer }}=x\left(a_{\text {InAs }}\right)+(1-x)\left(a_{\text {InP }}\right), v_{\text {layer }}=x\left(v_{\text {InAs }}\right)+(1-x)\left(a_{\text {InP }}\right)
$$


where equations (3) and (4) are written according to Vegard's law. Thus, the As composition of each layer with $\mathrm{As}_{2}$ /In ratios was determined from triple axis $\mathrm{x}$-ray analysis. Fig.1 shows the RSMs for the (004) and (224) reflection of a $1.5 \mu \mathrm{m}$ thick $\operatorname{In} \mathrm{As}_{0.4} \mathrm{P}_{0.6}$ epitaxial layer grown on 4step In $\mathrm{As}_{\mathrm{x}} \mathrm{P}_{1-\mathrm{x}}$ step graded buffer on a (100) InP substrate, respectively, using triple axis X-ray diffraction. From the RSM in Fig. 1(a), the magnitude of lattice tilt of the InAs ${ }_{0.4} \mathrm{P}_{0.6}$ layer was determined to be $\sim 22$ arcsec with respect to the InP substrate. Using the RSM from Figs. 1(a) and 1(b) the relaxation of each layer was determined; the level of relaxation was $100 \%, 98 \%$, and $93 \%$ for the $\operatorname{InAs} \mathrm{s}_{0.21} \mathrm{P}_{0.79}, \operatorname{In} \mathrm{As}_{0.32} \mathrm{P}_{0.68}$, and $\mathrm{InAs}_{0.4} \mathrm{P}_{0.6}$ layers respectively. This high level of relaxation is expected, as the layer thickness is far in excess of the critical thickness, and such step graded buffer layers are normally assumed to be fully relaxed. In this way, As composition
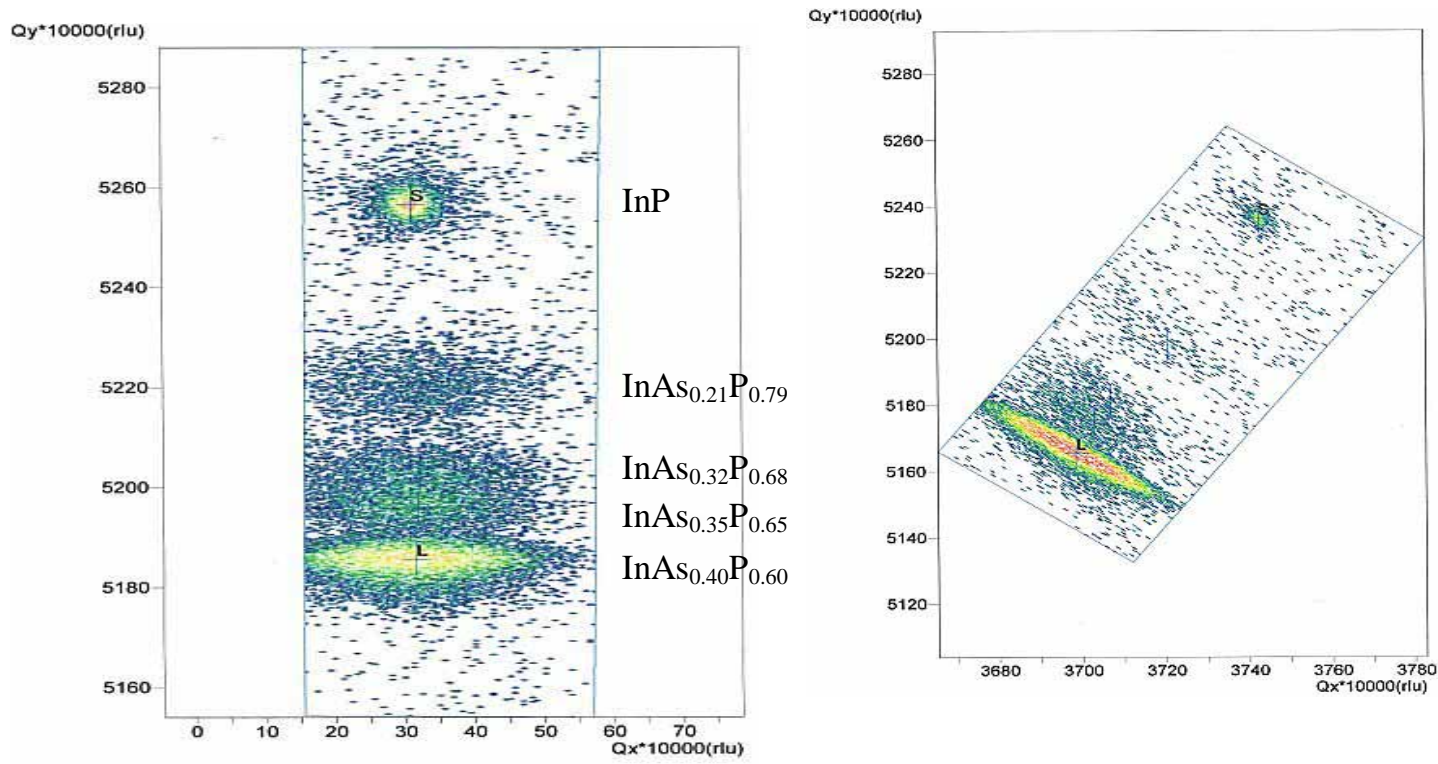

Fig. 1 (a) Symmetric (004) and (b) asymmetric (224) reciprocal space maps of a $1.5 \mu \mathrm{m}$ In $\mathrm{As}_{0.4} \mathrm{P}_{0.6}$ layer grown on step graded buffer, showing all the layers are almost fully relaxed.

was determined for each layer and thus an $\operatorname{In}_{A s} \mathrm{P}_{1-\mathrm{x}}$ composition calibration curve was produced by varying the $\mathrm{As}_{2} / \mathrm{In}$ ratio while maintaining a $\mathrm{P}_{2} / \mathrm{In}$ ratio of $7 / 1$, an In rate of $0.75 \mathrm{~mL} / \mathrm{s}$, and a growth temperature of $\sim 485^{\circ} \mathrm{C}$. Fig. 2 shows the As composition as a function of incident $\mathrm{As}_{2} /$ In flux ratio. One can conclude from Fig. 1 that the As composition in the $\operatorname{In} \mathrm{As}_{\mathrm{x}} \mathrm{P}_{1-\mathrm{x}}$ layers increases linearly with increasing $\mathrm{As}_{2} / \mathrm{In}$ ratios.

\section{Surface morphology}

The Nomarski microscopy image of the surface morphology of $\mathrm{Si}$-doped $\operatorname{InAs} \mathrm{As}_{0.32} \mathrm{P}_{0.68}$ layer is shown in Fig. 3(a). The well-developed surface crosshatch morphology indicates that the InAs $\mathrm{P}_{1-\mathrm{x}}$ graded buffer layers effectively managed the $1.04 \%$ lattice mismatch. The surface corrugations that form the crosshatch pattern have been related to the misfit dislocation (MD) network at the interface. [7,8]. Epitaxial films were also investigated using AFM to reveal the crosshatch and defects (if any). AFM images on different length scales have been taken to compare the top surface morphology of the epitaxial Si-doped $\operatorname{InAs}_{\mathrm{x}} \mathrm{P}_{1-\mathrm{x}}$ films with different As compositions in the $\operatorname{InAs}_{\mathrm{x}} \mathrm{P}_{1-\mathrm{x}}$ films. 


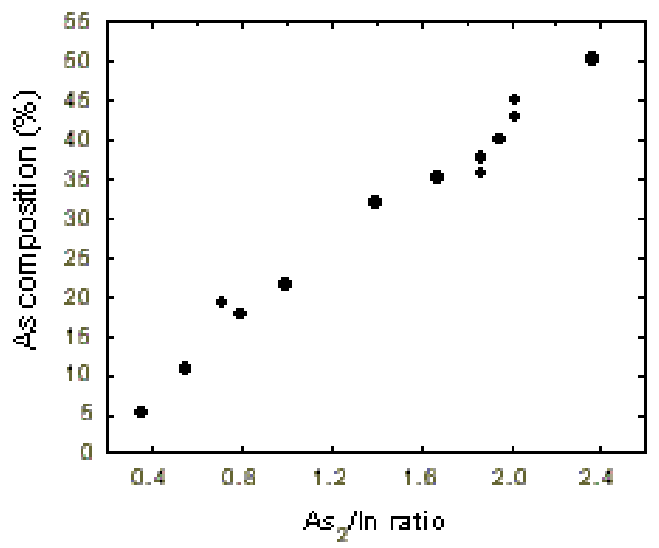

Fig. 2 As composition in $\operatorname{InAs} s_{x} P_{1-x}$ layer versus $\mathrm{As}_{2} /$ In ratio, measured by triple axis X-ray diffraction.

Fig. 3(b) shows AFM image of relaxed $\operatorname{In} A s_{0.32} \mathrm{P}_{0.68}$ film grown on 3-step $\operatorname{In} \mathrm{As}_{\mathrm{x}} \mathrm{P}_{1-\mathrm{x}}$ step graded buffer. The smooth appearance of the surface morphology of the relaxed layer is indicated by the low root mean square (rms) roughness; the rms roughness was about $3.3 \mathrm{~nm}$ over a $40 \mu \mathrm{m}$ x $40 \mu \mathrm{m}$ scan area.
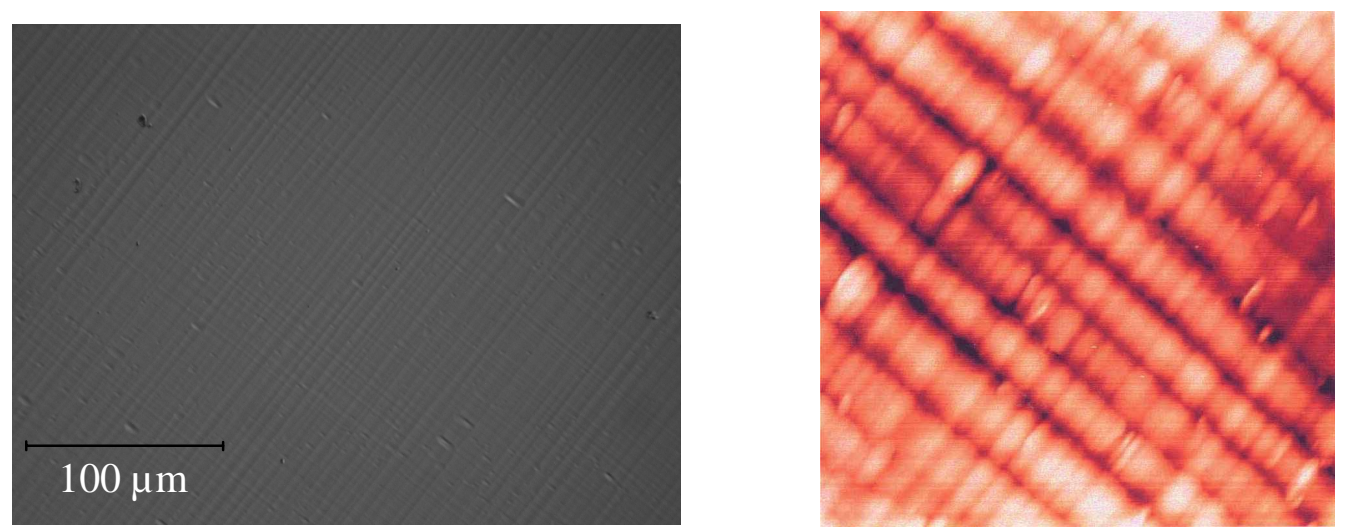

Fig. 3 (a) Normaski microscopy image of the surface of an $\operatorname{InAs} \mathrm{As}_{0.32} \mathrm{P}_{0.68}$ layer grown on 3-step graded InAs ${ }_{x} \mathrm{P}_{1-\mathrm{x}}$ buffer. (b) AFM image of the surface of an In $\mathrm{As}_{032} \mathrm{P}_{0.68}$ layer (same as in Fig. 3(a)). The measured rms roughness for this $40 \mu \mathrm{m} \times 40 \mu \mathrm{m}$ area scan was $3.3 \mathrm{~nm}$.

\section{Effect of As composition on carrier concentration and mobility}

The carrier concentration and the Hall mobility of Si-doped $\operatorname{InAs}_{\mathrm{x}} \mathrm{P}_{1-\mathrm{x}}(0<\mathrm{x}<0.50)$ layers were measured using Hall effect by the Van der Pauw method, for each As composition, these measurements were performed as a function of temperature between $20 \mathrm{~K}$ and $300 \mathrm{~K}$. All of the layers were grown with an identical $\mathrm{Si}$ cell temperature of $1004^{\circ} \mathrm{C}$ and thus ideally an identical Si flux. The electron concentration and carrier mobility of Si-doped $\operatorname{In} \mathrm{As}_{\mathrm{x}} \mathrm{P}_{1-\mathrm{x}}$ layers as a function of As compositions are shown in Fig. 4 for 300K and 80K, respectively. From Fig.4, it can be seen that the electron concentration is $\sim 3.5 \times 10^{16} \mathrm{~cm}^{-3}$ at $300 \mathrm{~K}$ and is the same for all As compositions studied in this paper. The electron mobility was observed to increase with increasing As content indicating that the threading dislocation density effect is minimized and thus the mobility follows band structure. The alloy scattering is not significant in InAsP in contrast to InGaAsP alloy [9]. Leheny et al [9] postulated on the basis of the compositional dependence of electron mobility in InGaAsP that alloy scattering associated with the cation sublattice may have a greater influence on scattering than the anion sublattice. This scattering was relatively weak for carriers with small effective masses, but can be strong for heavy carriers. Initial theoretical calculations on the electron mobility of $\operatorname{In} A s_{x} P_{1-x}$ by Ehrenreich [10] have also 
indicated that alloy scattering is not dominant and predicted at $300 \mathrm{~K}$ mobility of $14000 \mathrm{~cm}^{2} / \mathrm{Vs}$ for an alloy with a composition of $x=0.7$. This suggests that $\operatorname{In} A s_{x} P_{1-x}$ may be a better candidate for high mobility devices than the quaternary InGaAsP and even InGaAs. However, Chin [11] argued that ionized impurity scattering and alloy scattering are not very significant at room temperature where the contribution from the polar optical phonon scattering is almost sufficient to provide a reasonably good fit to experimental results at room temperature and ionized impurity scattering at $77 \mathrm{~K}$. In our case, the samples are grown using compositional step grading so that lattice strain effects are minimized, and hence the theoretical upper limit may possibly be achieved if the compensation ratio is low. We have determined the compensation ratios at $300 \mathrm{~K}$ and $80 \mathrm{~K}$ for As compositions of 0.10 and 0.50 using the theoretical figures by Chin. It was found that the samples have a compensation ratio of approximately 0.30 and 0.20 0.25 for $\mathrm{x}=0.10$ and 0.50 , respectively at $300 \mathrm{~K}$ and $80 \mathrm{~K}$, these compensation ratios agree well with the vapor phase epitaxial grown samples [11]. These relatively low compensation values are similar to those for high purity MBE and MOVPE grown GaAs [12] and $\operatorname{In}_{\mathrm{x}} \mathrm{Ga}_{1-\mathrm{x}}$ As [13].

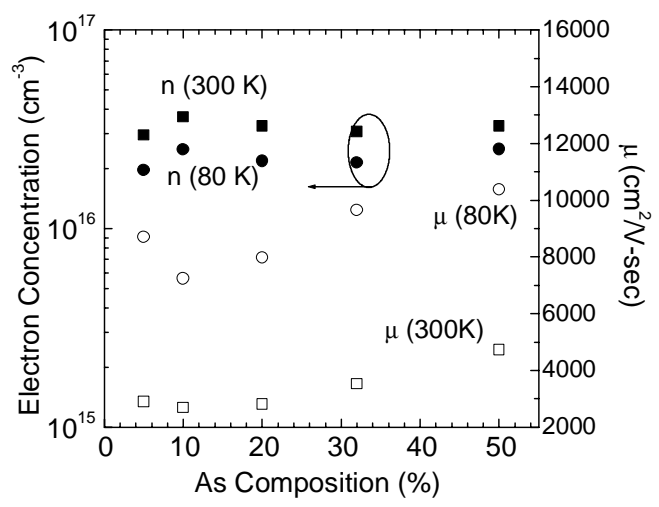

Fig. 4 Electron concentration and mobility of Si-doped $\operatorname{In} A s_{x} P_{1-x}$ as a function of As composition at both $300 \mathrm{~K}$ and $80 \mathrm{~K}$.

Effect of temperature on carrier concentration and mobility

Fig. 5 shows the temperature dependence of carrier concentration and mobility of Sidoped InAs ${ }_{\mathrm{x}} \mathrm{P}_{1-\mathrm{x}}$ samples with different As compositions.

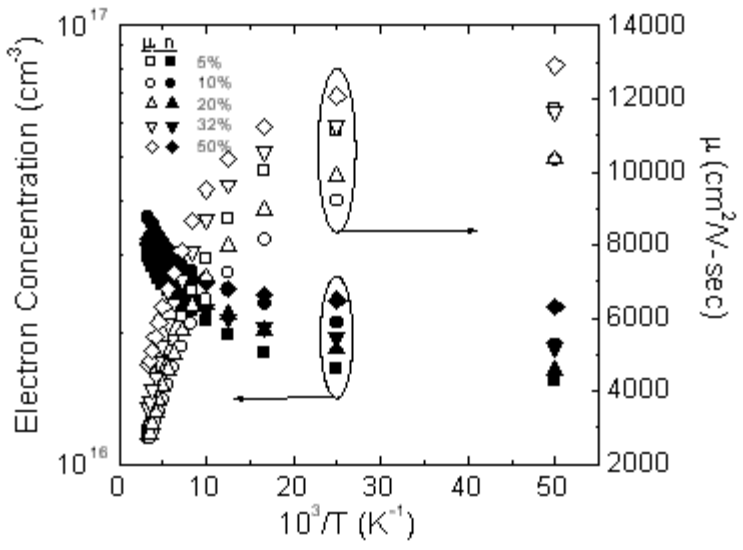

Fig. 5 Electron concentration and mobility of Si-doped $\operatorname{In} A s_{x} P_{1-x}$ as a function temperature with different As compositions. 
The mobility was found to be $10372 \mathrm{~cm}^{2} /$ Vs for $\mathrm{x}=0.50$ at $80 \mathrm{~K}$, which has a low compensation ratio of $0.2-0.25$. These samples are not affected by lattice mismatch and shows low compensation ratios. At a constant electron concentration of $3.5 \times 10^{16} \mathrm{~cm}^{-3}, 300 \mathrm{~K}$ carrier mobility increased from 2700 to $4732 \mathrm{~cm}^{2} / \mathrm{Vs}$ with As mole fraction increasing from 0.05 to 0.50. The activation energy of $\mathrm{Si}$ donor extracted from the slope of the carrier concentration versus 1000/T plot at higher temperature was found to be $\sim 9.0-14.0 \mathrm{meV}$ with different As compositions. It can be assumed to be the same for all As compositions, since the slope in Fig. 5 can vary depending on the number of data points used.

\section{CONCLUSIONS}

Relaxed high purity Si-doped $\operatorname{In} \mathrm{As}_{\mathrm{x}} \mathrm{P}_{1-\mathrm{x}}$ layers with As compositions ranging from 0.05 to 0.50 were grown and characterized using solid source $\mathrm{MBE}$ as the growth tool. AFM determined an rms roughness of only $2.3 \mathrm{~nm}$ over the $40 \mu \mathrm{m}$ x $40 \mu \mathrm{m}$ area scan. The As composition of $\operatorname{InAs}_{\mathrm{x}} \mathrm{P}_{1-\mathrm{x}}$ layers were determined by triple axis x-ray diffraction measurements. The As incorporation rate was controlled by changing the $\mathrm{As}_{2} / \mathrm{In}$ flux ratio and it increased linearly with the $\mathrm{As}_{2} / \mathrm{In}$ flux ratio. Near complete relaxation of final $\operatorname{In}_{\mathrm{As}} \mathrm{P}_{\mathrm{x}} \mathrm{P}_{1-\mathrm{x}}$ epilayers with minimum lattice tilt as well as well developed surface crosshatch morphologies were achieved, indicating the effectiveness of the InAs $\mathrm{P}_{\mathrm{x}} \mathrm{P}_{1-\mathrm{x}}$ graded buffers in controlling strain relaxation. At a constant electron carrier concentration of $\sim 3.5 \times 10^{16} \mathrm{~cm}^{-3}$, the $300 \mathrm{~K}$ carrier mobility increased from 2700 to $4732 \mathrm{~cm}^{2} / \mathrm{V}$-sec with increasing As mole fraction from 0.05 to 0.50 . The structural quality and the electrical performance indicate the potential of SSMBE for preparing high quality $\mathrm{InAs}_{\mathrm{x}} \mathrm{P}_{1-\mathrm{x}}$ alloys for high-speed device applications.

\section{ACKNOWLEDGEMENT}

This work is supported by the National Science Foundation under grant number DMR-0076362.

\section{REFERENCES}

1. J. P. R. David, M. Hopkinson, P. N. Stavrinou, and S. K. Haywood, J. Appl. Phys. 78, 3330 (1995).

2. M. R. Leyes, H. Titze, L. Samuelson, and J. Petruzzello, J. Crystal Growth 93, 504 (1988).

3. T. Miura, K. Onabe, X. Zhang, Y. Nitta, S. Fukatsu, Y. Shiraki, and R. Ito, Jpn. J. Appl. Phys., Part 2 30, L664 (1991).

4. T. Anan, S. Sugou, K. Nishi, and T. Ichihashi, Appl. Phys. Lett. 63, 1047 (1993).

5. B. X. Yang, L. He, and H. Hasegawa, J. Electron. Mater. 25, 379 (1996).

6. R. R. Hess, C. D. Moore, and M. S. Goorsky, J. Phys. D: Appl. Phys. 32, A16 (2000).

7. S. Y. Shiryaev, F. Jensen, and J. W. Petersen, Appl. Phys. Lett. 64, 3305 (1994).

8. R. Beanland, M. Aindow, T. B. Joyce, P. Kidd, M. Lourenco, and P. J. Goodhew, J. Crystal Growth 149, 1 (1995).

9. R.F. Lehey, A. A. Ballman, J. C. Dewinter, R. E. Nahory, and M. A. Pollack, J. Electron. Mater. 9, 561 (1980).

10. H. Enhenreich, J. Phys. Chem. Solids 12, 97 (1959).

11. V. W. L. Chin, J. Phys. Chem. Solids 53, 897 (1992).

12. C. R. Stanely, M. C. Holland, A. H. Kean, M. B. Stanaway, R. T. Grimes, and J. M.

Chamberlain, Appl. Phys. Lett. 64, 3305 (1994).

13. V. W. L. Chin, T. Osotchan, and T. L. Tansley, J. Phys. Chem. Solids 53, 897 (1992). 